\title{
Typological Characteristics of Small Rural Cities
}

\author{
Masao Ishii ${ }^{1}$, Satoshi Yamada*², Takashi Kuroiwa ${ }^{3}$, Mitsuhito Matsubara ${ }^{3}$ and Hirotomo Ohuchi ${ }^{4}$
}

\author{
${ }^{1}$ Development Planning Institute, Inc., Ms. Eng., Japan \\ ${ }^{2}$ Assistant Professor, Department of Integrated and Eng. for Sustainable Society, Faculty of Science and Eng., Chuo Univ., Dr. Eng., Japan \\ ${ }^{3}$ Professor, Department of Electrical and Electronic Engineering, College of Industrial Technology, Nihon University, Dr. Eng., Japan \\ ${ }^{4}$ Professor, Department of Architecture, College of Industrial Technology, Nihon University, Dr. Eng., Japan
}

\begin{abstract}
Understanding small rural cities from a national planning perspective is important when considering their revitalization or independence. Pattern analysis is one method used to foster this understanding. One of the main purposes of pattern analysis is to understand important indicators to grasp the complete picture. In this study, authors performed pattern analysis on small rural cities in Japan, with populations ranging from 30,000 to 100,000 people. The 26 indicators were obtained from the designated Bureau of Statistics, who obtained them from sources such as the national census data. The units of all the indicators were different. The indicators did not necessarily follow a normal distribution because the objects were assumed to be small rural cities. Through this study, authors could understand indicators that form the basis for classifying cities using principal component analysis. Through this study and the five main patterns obtained, authors could understand three principal components for classification: "urban locational infrastructure," "urban spatial formation," and "industrial vitality."
\end{abstract}

Keywords: small rural cities; regional area; typification of cities; principal component analysis

\section{Introduction}

In recent years, regional development trends have shifted from an exterior to an interior type along with a growing awareness of civil administrative innovation and practical activities. Specifically, this signifies a shift in emphasis from enhancing local production capacity to creating and activating the charm of urban and local communities. This implies that the idea of independence and development has changed from material elements to non-material elements. These changing thought trends indicate the importance of regional formation theory, which contemplates the basic construction of humans and society. Authors need to reform the planning system in response to societal changes. This study aims, based on the concepts discussed earlier, to construct a theory of regional planning that accounts for the characteristics of each small rural city.

Authors have entered an era of population decline. In particular, the population in regional areas ${ }^{1}$ is

*Contact Author: Satoshi Yamada, Assistant Professor, Dept. of Integrated and Engineering for Sustainable Society, Faculty of Science and Engineering, Chuo University 1-13-27, Kasuga,Bunkyo-ku, Tokyo, 112-8551, Japan Tel: +81-3-3817-7268 Fax: +81-3-3817-7268

E-mail: satoshi.bon@gmail.com

(Received April 15, 2013 ; accepted March 7, 2014 ) expected to continue declining in the future. This poses a unique challenge for small rural cities $^{2}$, because their formation process positions them in a severe regional economic environment. In addition, ongoing municipality mergers are currently forming new small rural cities, while existing communities continue to expand their borders. Following a different principle to urbanization, modernization, globalization, and production enhancement of rural society, small rural cities and rural districts (agricultural, mountain, and fishing villages) are searching for attractive living environments. As such, social expectations continue to strengthen. Human scale, community participation, sustainability, and diversity are concepts that can be used to understand an analysis of urbanization processes and related mechanisms based on new local community creations and small local cities. Related studies include Cheong-Ho Park et al. (2014), who determined that activities such as cultural promotion, enlightenment, and grassroots affect the formation of social capital. Min Jung et al. (2014) reviewed the literature to discuss the sustainable development of a city. They used Curitiba in Brazil as a case study to examine the significance of sustainability. Another study, by Hatem Mahmoud (2011) et al., discussed the process of participatory planning in urban developmental projects through a case study of a webbased civil activity system. These small- and medium- 
Table 2. List of Analyzed Indicators

\begin{tabular}{|c|c|c|c|c|}
\hline & No. & Component & Indicator & Method of Calculation \\
\hline \multirow{9}{*}{ 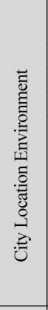 } & 1 & Transportation conditions & Stage of High-Speed Transportation (1995) & $\begin{array}{l}\text { The ratio of the total number of the following three features nationwide: Highway interchange, Shinkansen } \\
\text { station, and the number of airports located within } 30 \mathrm{~km} \text { of the small rural town. }\end{array}$ \\
\hline & 2 & \multirow{2}{*}{ Circumstances leading to mergers } & Number of Old Towns and Villages (1950) & Number of autonomous towns and villages at the time of merger. \\
\hline & 3 & & Degree of Prominence of Largest City Population (1950) & Population of autonomous towns and villages at the time of merger/Total population. \\
\hline & 4 & Geographical situations & Ratio of Inhabitable Land Area (1995) & Ratio of total land area to inhabitable land area. \\
\hline & 5 & \multirow{3}{*}{ City formation conditions } & Total Population (1960) & Total population value. \\
\hline & 6 & & $\begin{array}{l}\text { Concentration of Dwelling Units (DID Population } \\
\text { Ratio) (1960) }\end{array}$ & DID district population/Total population. \\
\hline & 7 & & $\begin{array}{l}\text { Ratio of Secondary and Tertiary Industry (Urban Oriented } \\
\text { Industry)(1960) }\end{array}$ & (Secondary industry + Tertiary industry) Working population $\times 100 \%$ \\
\hline & \multirow{2}{*}{$\begin{array}{l}8 \\
9\end{array}$} & \multirow[b]{2}{*}{ Existence and influence of surrounding cities } & Population Size within 30-km Sphere (1990) & Value of population size within $30-\mathrm{km}$ sphere. \\
\hline & & & Potential Population Size within 30-km Sphere (1990) & $\begin{array}{l}\text { Sum of the direct distance }(\mathrm{km}) / \text { Population of cities and rural cities within a 30-km sphere of the small } \\
\text { rural city. }\end{array}$ \\
\hline \multirow{10}{*}{ 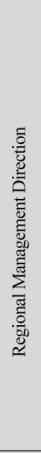 } & 10 & \multirow{2}{*}{ Industrialization efforts } & $\begin{array}{l}\text { Rate of Change in Secondary Industry Worker Population } \\
\text { Ratio }(1990 / 1970)\end{array}$ & Number of second-tier industry workers in 1990/Number of secondary industry workers in 1970. \\
\hline & 11 & & $\begin{array}{c}\text { Rate of Change in Industrial/Construction Worker Population } \\
\text { Ratio }(1990 / 1970)\end{array}$ & Number of industrial/construction workers in 1990/Number of industrial or construction workers in 1970. \\
\hline & 12 & \multirow{2}{*}{ Infrastructure formation efforts } & Rate of Change of Investment Expenses (1990/1970) & $\begin{array}{l}\text { Ratio of investment expenditures to total expenditures in 1990/Ratio of investment expenditures to total } \\
\text { expenditures in } 1970 \text {. }\end{array}$ \\
\hline & 13 & & $\begin{array}{l}\text { Rate of Change in High Magnification of Present } \\
\text { Products }(1990 / 1970)\end{array}$ & $\begin{array}{l}\text { Outstanding municipal bonds in 1990/Proportion of same numerical value of standard financial scale from } \\
1970 \text {. }\end{array}$ \\
\hline & 14 & Life style and welfare efforts & $\begin{array}{c}\begin{array}{c}\text { Rate of Change of People Hospitalized in Bed per Thousand } \\
\text { People }(1990 / 1970)\end{array}\end{array}$ & $\begin{array}{l}\text { Number of people hospitalized in bed per thousand people in } 1990 / \text { Number of people hospitalized in bed per } \\
\text { thousand people in } 1970 \text {. }\end{array}$ \\
\hline & 15 & \multirow[t]{2}{*}{ Urbanization efforts } & Rate of Change of DID Population Ratio (1990 / 1970) & $\begin{array}{l}\text { Proportion of DID district population versus total population in 1990/Proportion of DID district population } \\
\text { versus total population in } 1970 \text {. }\end{array}$ \\
\hline & 16 & & Rate of Exponential City $\mathrm{Ch}$ & Ratio of same numerical values of DID district population x DID district area in 1970 compared to 1990. \\
\hline & 17 & \multirow{3}{*}{ Localization efforts } & $\begin{array}{l}\text { Rate of Change in Tertiary Industry Worker Population } \\
\text { Ratio }(1990 / 1970)\end{array}$ & Number of tertiary industry workers in 1990/Number of third-tier industry workers in 1970. \\
\hline & 18 & & $\begin{array}{l}\text { Rate of Change of Service Industry Workers/Commercial } \\
\text { Industry Workers Population }(1990 / 1970)\end{array}$ & $\begin{array}{l}\text { Ratio of service industry workers or commercial industry workers in 1990/Ratio of service industry workers } \\
\text { or commercial industry workers in } 1970 \text {. }\end{array}$ \\
\hline & 19 & & Regional Public Facility Development $(1990 / 1970)$ & $\begin{array}{l}\text { Number of developed public facilities within a } 30-\mathrm{km} \text { sphere of the small rural city (universities/colleges, } \\
\text { libraries, museums, art galleries, halls, and shopping centers). }\end{array}$ \\
\hline \multirow{7}{*}{ 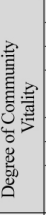 } & 20 & \multirow{2}{*}{ Localization efforts } & Financial Capability Index (1991) & Three-year average percentage of the amount of basic finances; Income/Basic financial needs. \\
\hline & 21 & & Ratio of Current Account Balance $(1990 / 1970)$ & ce operating costs/Prop \\
\hline & 22 & \multirow[b]{2}{*}{ Population structure } & Rate of Population Change (1990) & Population in 1990/Populatic \\
\hline & 23 & & Rate of Subordinate Population Index Change (1990) & $\begin{array}{l}1990 \text { population value for ( } 0 \text { to } 14 \text { years old) }+(\text { over } 65 \text { years old) Proportion of population (15-64 years } \\
\text { old) with same numerical value in } 1970 \text {. }\end{array}$ \\
\hline & 24 & \multirow{2}{*}{ Industrial vitality } & Amount of Taxable Income Per Capita (1990) & Earned income - Personal deduction - Other deduction/Total population. \\
\hline & 25 & & Proportion of Population in Primary Industry (1990) & $\begin{array}{l}\text { Working population in primary industry/Working population in primary. secondary, and tertiary industries. } \\
\text { Retail sales of small rural cities/Proportion of same numerical value of the number of small rural city }\end{array}$ \\
\hline & 26 & Unifying capability & Retail Attraction Coefficient (1991) & $\begin{array}{l}\text { Retail sales of small rural cities/Proportion of sar } \\
\text { households located in prefectures. }\end{array}$ \\
\hline
\end{tabular}

Table 1. Subject Analysis Overview

\begin{tabular}{|c|c|c|c|c|c|c|c|c|}
\hline \multicolumn{3}{|c|}{ Tohoku } & \multicolumn{3}{|c|}{ Chubu } & \multicolumn{3}{|c|}{ Shikoku } \\
\hline Prefecture & No. & City & Prefecture & No. & City & Prefecture & No. & City \\
\hline \multirow{3}{*}{ Aomori } & 1 & Kuroishi & \multirow{4}{*}{ Toyama } & 38 & Uozu & \multirow{2}{*}{ Kagawa } & 72 & Zentsuji \\
\hline & 2 & Goshogawara & & 39 & Himi & & 73 & Kanonji \\
\hline & 3 & Towada & & 40 & Namerikawa & \multirow{3}{*}{ Ehime } & 74 & Ozu \\
\hline \multirow{6}{*}{ Iwate } & 4 & Ofunato & & 41 & Tonami & & 75 & Kawanoe \\
\hline & 5 & Mizusawa & \multirow{3}{*}{ Ishikawa } & 42 & Wajima & & 76 & Iyomishima \\
\hline & 6 & Hanamaki & & 43 & Kaga & \multirow{3}{*}{ Kochi } & 77 & Tosa \\
\hline & 7 & Kitakami & & 44 & matto & & 78 & Suzaki \\
\hline & 8 & Kuji & \multirow{3}{*}{ Fukui } & 45 & Komatsu & & 79 & Nakamura \\
\hline & 9 & Esashi & & 46 & Ono & & Kyus! & \\
\hline \multirow{5}{*}{ Miyagi } & 10 & Furukawa & & 47 & Sabae & \multicolumn{2}{|c|}{ Prefecture No. } & City \\
\hline & 11 & Kesennuma & \multirow{4}{*}{ Yamanash } & 48 & Fujiyoshida & \multirow{9}{*}{ Fukuoka } & 80 & Yanagawa \\
\hline & 12 & Shiroishi & & 49 & Tsuru & & 81 & Amagi \\
\hline & 13 & Natori & & 50 & Yamanashi & & 82 & Chikugo \\
\hline & 14 & Kakuda. & & 51 & Otsuki & & 83 & Okawa \\
\hline \multirow{4}{*}{ Akita } & 15 & Honjo & \multirow{7}{*}{ Nagano } & 52 & Komoro & & 84 & Yukuhashi \\
\hline & 16 & Oga & & 53 & Ina & & 85 & Buzen \\
\hline & 17 & Yuzawa & & 54 & Komagane & & 86 & Ogori \\
\hline & 18 & Omagari & & 55 & Nakano & & 87 & Chikushino \\
\hline \multirow{6}{*}{ Yamagata } & 19 & Sagae & & 56 & Omachi & & 88 & Munakata \\
\hline & 20 & Kaminoyama & & 57 & Chino & \multirow{4}{*}{ Saga } & 89 & Tosu \\
\hline & 21 & Murayama & & & Shiojiri & & 90 & Imari \\
\hline & 22 & Nagai & \multirow{2}{*}{\multicolumn{3}{|c|}{ Chugoku }} & & 91 & Takeo \\
\hline & 23 & Tendo & & & & & 92 & Kashima \\
\hline & 24 & Higashine & \multirow{3}{*}{$\begin{array}{c}\text { Prefecture } \\
\text { Tottori }\end{array}$} & No. & City & \multirow{4}{*}{ Kumamoto } & 93 & Tamana \\
\hline \multirow{5}{*}{ Fukushima } & 25 & Haramachi & & 59 & Kurayoshi & & 94 & Hondo \\
\hline & 26 & Sukagawa & & 60 & Sakaiminato & & 95 & Yamaga \\
\hline & 27 & Kitakata & \multirow{4}{*}{ Shimane } & 61 & Masuda & & 96 & Uto \\
\hline & 28 & Soma & & 62 & Ota & Miyazaki & 97 & Saito \\
\hline & 29 & Nihonmatsu & & 63 & Yasugi & & 98 & Izumi \\
\hline & Chu & & & 64 & Hirata & Kagoshima & 99 & Ibusuki \\
\hline & 30 & Ojiya & Okayama & 65 & Ihara & & 100 & Kokubu \\
\hline & 31 & Tokamachi & & 66 & Soja & & & \\
\hline & 32 & Mitsuke & & 67 & Innoshima & & & \\
\hline Nigata & 33 & Murakami & Hiroshima & 68 & Futyu & & & \\
\hline & 34 & Tsubame & & 69 & Miyoshi & & & \\
\hline & 35 & Itoigawa & & 70 & Otake & & & \\
\hline & 36 & Gosen & Yamaguchi & $|71|$ & Yanai & & & \\
\hline & $37 \mid$ & Shirane & & & & & & \\
\hline
\end{tabular}

sized cities attract national and global attention as places that provide a lifestyle for those who emphasize a sense of value.

Moreover, even in the Japanese National Spatial Planning guidelines, the challenge of positioning a small rural city is becoming increasingly important. For example, Odagiri (2007) highlighted that active positioning in the National Land Policy is indispensable. Furthermore, the "Self-Sustainability Settlement Plan Study Group Report" by the Ministry of Internal Affairs and Communications' (2008) SelfSustainability Settlement ${ }^{3}$ Plan Study Group indicates aggregating functionality in cities with a population of 50,000 people or more, and movement in the direction of establishing independent areas with the help of neighboring communities. "Small rural cities" are considered important in Japan in terms of National Spatial Planning for the future. Therefore, this study aims to contribute to the development of a new theory of regional planning for the construction of small rural cities. In addition, the study aims to analyze pattern formation of small rural cities to understand the formation of those patterns considered important for comprehending their overall structure.

\section{Research Outline}

\subsection{Research Objectives and Subjects}

Fundamentally, it is important to have small rural cities as the subject of study because municipality mergers ${ }^{4}$ are ongoing. However, there are cases where both newly merged municipalities and those not yet ready to be merged exist. It is possible, with restrictions in the analysis of the study methodology, to make these cases subjects of research. For this reason, authors included subjects in our study up to the induction of the concept of wide-area mergers (1990-1995) (referred to as the great merger of the Showa period). 
In particular, among rural areas, except for Hokkaido and Okinawa, which differ from the historical process of formation of peripheral non-metropolitan areas (rural area I), authors selected 101 autonomous subjects from 28 prefectures with a population of from 30,000 to 100,000 (see Table 1.).

\subsection{Method of Analysis}

The purpose of this study was to use statistics to better understand current conditions in small rural cities. Therefore, authors first identified statistical values to represent small rural cities. For the purpose of our study, authors consider the growth and formation characteristics of cities to be determined by the degree of community vitality (dynamic achievements). Community vitality is achieved on two axes: (1) the axis of the city location environment, which refers to future conditions that affect the formation of a city (extrinsic conditions); and (2) the axis of regional management direction, which is an approach reflecting intrinsic efforts. Furthermore, authors established components thought to comprise respective axes or to be fundamental factors. There were five components pertaining to "city location environment," including traffic conditions, circumstances leading to mergers, and conditions at the time the city was formed. There were also five components pertaining to the "regional management direction," including industry efforts, efforts in building infrastructure, and urbanization efforts. Furthermore, the "degree of community vitality" was hypothesized to comprise four components: financial capability (responding to industrialization efforts), industrial vitality (responding to infrastructure formation efforts), unifying capability (responding to localization and urbanization efforts), and population structure (responding to lifestyle and welfare efforts). Authors prepared a basic framework in accordance with these fundamental concepts based on our assumption that authors could use these factors for each city, as shown in Table 2. Authors selected statistical indicators based on a high degree of functional representativeness and a low degree of redundancy with other functions. Furthermore, these indicators were obtained from designated Bureaus of Statistics in Japan, who had data from the national census, for example.

Second, authors conducted a principal component analysis using the hypothesized statistical indicators to verify if previously hypothesized indicators could be statistically used to study small rural cities, to identify principal indicators needed for overall understanding, and to determine the relation between indicators. Specifically, authors first examined the correlation/ non-correlation of indicators against each other. The indicator with the higher correlation value was used as a representation. Authors then conducted a principal component analysis to verify if the subject can be statistically assessed based on eigenvalues and contribution ratios using the hypothesized indicator group. Third, authors discussed the principal component forming the subject's system by using the principal component loads of each indicator.

Last, authors performed a typological analysis of the scores from the principal component analysis. This was to statistically understand the characteristics of small rural cities in the system formed by the indicator group. Specifically, authors performed a typification using the scores of small rural cities from the principal component analysis with the aid of the SOM-Ward method. Authors could then examine the typological characteristics together with individual indicators after reading the distribution of scores of the principal components and the trend of average values within the types.

Based on this, authors studied principal components and typological characteristics to systematically understand the current situation of small rural cities.

\section{Principal Component Analysis}

After considering single correlation coefficients and the decorrelation of obtained statistical values, the 24 indicators shown in Table 3. were used to conduct a principal component analysis. The principal component loads are presented in Table 3., while the eigenvalues, contribution ratios, and cumulative contribution ratios are shown in Table 4 . Since the cumulative contribution ratio reached $83.44 \%$ with the third principal component, as shown in Table 4., the third principal components were adopted as principal components. Based on principal component loads (see Table 3.), the three types of principal components were considered as follows.

Principal component 1: This component shapes regional characteristics, with an eigenvalue of 801.61 and contribution ratio of $43.30 \%$. The principal component load shown in Table 3 . reveals relatively large positive contributions to the "stage of highspeed transportation," "ratio of inhabitable land area," "potential population size within a $30 \mathrm{~km}$ sphere," "rate of population change," and "amount of taxable income per capita." Negative contributions were made to the "total population," "concentration of dwelling units (DID population ratio)," "rate of change in primary industry population," and "retail attraction coefficient." Based on this, principal component 1 was considered to be an axis representing the degree of "urban location infrastructure."

Principal component 2: This component shapes regional characteristics, with an eigenvalue of 396.74 and a contribution ratio of $21.43 \%$. The principal component load shown in Table 3. reveals a large positive contribution to the "ratio of inhabitable land area" and the "concentration of dwelling units (DID population ratio)," and a smaller positive contribution to the "ratio of secondary and tertiary industry (urban oriented industry)." In contrast, there was a relatively large negative contribution to the "stage of high-speed 
transportation," and smaller negative contributions to the "rate of subordinate population index change," "regional public facility development," "rate of change in tertiary industry worker population," and "rate of population change." Based on this, principal component 2 was considered to be an axis representing the degree of "urban spatial formation."

Principal component 3: This component shapes regional characteristics, with an eigenvalue of 346.56 , a contribution ratio of $18.72 \%$, and a cumulative contribution ratio of $83.44 \%$. The principal component load shown in Table 3 . reveals a relatively large positive contribution to the "rate of population change," "regional public facility development," "amount of taxable income per capita," "financial capability index," and "rate of change of service industry/commercial industry workers population." In contrast, a relatively large negative contribution to the "stage of high-speed transportation," "total population," "ratio of inhabitable land area," "rate of subordinate population index change," and "proportion of population in primary industry" was evident, as well as a smaller negative contribution to the "rate of change of investment expenses." Principal component 3 was considered an axis representing "industrial vitality."

\section{Typological Characteristics}

A typological analysis was conducted to consider small rural cities formed by various factors. Typification was performed using the principal component scores obtained in Section 3 and a selforganizing map (SOM-Ward) ${ }^{5}$. The resulting selforganizing map is shown in Fig.1. The average values of the principal components within each type are shown in Table 5., and the names of the cities categorized in each type are shown in Table 6. Based on this information, authors obtained the typological characteristics described below. Furthermore, type E was excluded from the consideration of typological characteristics as it had relatively significant variance in sampled lots.

Type A: Of the 100 small rural cities that were the subjects of our study, 33 cities (33\% of our subjects) belong to Type A. When these cities were surveyed based on the individual indicators shown in Table 2., the following characteristics emerged: (1) Some municipalities composed the core of their respective cities among the constituent towns and villages prior to the mergers. These municipalities had more urban characteristics, such as urban industry ${ }^{6}$, which is a requirement stipulated by the Local Autonomy Act as a condition for a city to come into existence. (2) These municipalities manifested clear signs of fragility with regard to infrastructure for high-speed transportation and centrality. They tended to be widespread entities, with relatively unfavorable external environmental conditions. (3) Regional management approaches and direction for industrialization efforts were weak.
Table 3. Component Load

\begin{tabular}{|c|c|c|c|c|}
\hline No. & Indicator & $\begin{array}{c}\text { Principal } \\
\text { Component No.1 }\end{array}$ & $\begin{array}{c}\text { Principal } \\
\text { Component No.2 }\end{array}$ & $\begin{array}{l}\text { Principal } \\
\text { Component No.3 }\end{array}$ \\
\hline 1 & $\begin{array}{l}\text { Stage of High-Speed } \\
\text { Transportation }\end{array}$ & 0.735749712 & 0.572221986 & -0.360683631 \\
\hline 2 & Number of Old Towns and Villages & -0.008638328 & 0.040947637 & -0.043675478 \\
\hline 3 & $\begin{array}{c}\text { Degree of Prominence of Largest } \\
\text { City Population }\end{array}$ & -0.13739248 & -0.03869104 & -0.08712759 \\
\hline 4 & Ratio of Inhabitable Land Area & 0.753061407 & -0.62272532 & -0.212309079 \\
\hline 5 & Total Population & -0.224954329 & -0.032572167 & -0.326112602 \\
\hline 6 & $\begin{array}{c}\text { Concentration of Dwelling Units } \\
\text { (DID Population Ratio) }\end{array}$ & -0.212426101 & -0.174893725 & -0.175379206 \\
\hline 7 & $\begin{array}{l}\text { Ratio of Secondary and Tertiary } \\
\text { Industry (Urban Oriented Industry) }\end{array}$ & -0.119681277 & -0.081826242 & -0.018875612 \\
\hline 9 & $\begin{array}{l}\text { Population Size within 30-km } \\
\text { Sphere }\end{array}$ & 0.654371967 & 0.110720397 & 0.187963839 \\
\hline 10 & $\begin{array}{l}\text { Rate of Change in Secondary } \\
\text { Industry Worker Population Ratio }\end{array}$ & -0.00307664 & -0.028669598 & -0.05720655 \\
\hline 11 & $\begin{array}{c}\text { Rate of Change in } \\
\text { Industrial/Construction Worker }\end{array}$ & -0.010394352 & 0.046452922 & -0.05615009 \\
\hline 12 & $\begin{array}{l}\text { Rate of Change of Investment } \\
\text { Expenses }\end{array}$ & -0.057124715 & 0.101705141 & -0.119863674 \\
\hline 13 & $\begin{array}{c}\text { Rate of Change in High } \\
\text { Magnification of Present Products }\end{array}$ & -0.091944811 & 0.045302945 & 0.113904239 \\
\hline 14 & $\begin{array}{c}\text { Rate of Change of People } \\
\text { Hospitalized in Bed per Thousand }\end{array}$ & 0.097785432 & -0.076682034 & 0.092358777 \\
\hline 15 & $\begin{array}{c}\text { Rate of Change of DID Population } \\
\text { Ratio }\end{array}$ & 0.038039584 & -0.009977143 & 0.066005661 \\
\hline 16 & Rate of Exponential City Change & 0.284829841 & 0.052211219 & 0.13452947 \\
\hline 17 & $\begin{array}{l}\text { Rate of Change in Tertiary } \\
\text { Industry Worker Population Ratio }\end{array}$ & 0.247169485 & 0.1401225 & 0.02264444 \\
\hline 18 & $\begin{array}{l}\text { Rate of Change of Service } \\
\text { Industry Workers/Commercial } \\
\text { Industry Workers Population }\end{array}$ & -0.017892895 & 0.044607913 & 0.125109376 \\
\hline 19 & $\begin{array}{l}\text { Regional Public Facility } \\
\text { Development }\end{array}$ & 0.129472866 & 0.199017942 & 0.453757998 \\
\hline 20 & Financial Capability Index & 0.26616799 & 0.051550902 & 0.10936756 \\
\hline 22 & Rate of Population Change & 0.6771565 & 0.104877414 & 0.725305749 \\
\hline 23 & $\begin{array}{l}\text { Rate of Subordinate Population } \\
\text { Index Change }\end{array}$ & 0.058027302 & 0.224860262 & -0.262503995 \\
\hline 24 & $\begin{array}{l}\text { Amount of Taxable Income Per } \\
\text { Capita }\end{array}$ & 0.354125732 & 0.060699953 & 0.252558423 \\
\hline 25 & $\begin{array}{c}\text { Proportion of Population in Primary } \\
\text { Industry }\end{array}$ & -0.156695312 & -0.071528516 & -0.255808207 \\
\hline 26 & Retail Attraction Coefficient & -0.15673545 & -0.071645904 & 0.023104738 \\
\hline
\end{tabular}

Table 4. Contribution Ratios

\begin{tabular}{|l|r|r|r|}
\hline & Eigenvalue & Contributing Rate & Cumulative Contribution Ratio \\
\hline Principal Component No.1 & 801.60 & $43.30 \%$ & $43.30 \%$ \\
\hline Principal Component No.2 & 396.74 & $21.43 \%$ & $64.73 \%$ \\
\hline Principal Component No.3 & 346.56 & $18.72 \%$ & $83.44 \%$ \\
\hline
\end{tabular}

The results of typification were derived with such characteristics in mind. First, as shown in Table 5., the average values of principal components were 28.42 for principal component 1 (urban location infrastructure), -2.25 for principal component 2 (urban spatial formation), and 9.70 for principal component 3 (industrial vitality). A comparison of these results, with the principal component average values of types $B, C$, and $D$, revealed that the urban localization infrastructure of this type was weaker than the other types. This type had a positive value (9.70) for industrial vitality, while all three other types had negative values, making these two features the characteristics of this type. Furthermore, the results of the SOM indicated that principal components 1 and 3 had lower values and relatively concentrated distributions, while principal component 2 had a more dispersed distribution characteristic than 1 and 3 . In light of these individual aspects, this type can be characterized by gaps between cities with regard to community vitality, which is a dynamic result of the regional management direction for improving starkly unfavorable location environments. 
Type B: Of the 100 small rural cities that were the subjects of our study, 19 cities (19\% of our subjects) belong to Type B. When these cities were surveyed based on the individual indicators shown in Table 2., the following characteristics emerged: (1) As their core functions, many of these cities possessed widespread commercial and industrial functions in industries such as marine products, local industry, and tourism. (2) Today, many have a weakened regional economy infrastructure, as many of these industries have lost vitality and need responsive action to initiate renewed vitalization. (3) These cities were once a central location for a broad municipal area, but this role decayed consequent to upgrading and substantiation of transportation systems.

The results of typification were derived with these characteristics in mind. First, the average values of the principal components, as shown in Table 5., were -6.46 for principal component 1 (urban location infrastructure), 11.32 for principal component 2 (urban spatial formation), and -0.77 for principal component 3 (industrial vitality). A comparison of this result with the principal component average values of types A, C, and $\mathrm{D}$ revealed little difference between the average values of these principal components. A characteristic of this type is that it ranks in the middle for respective principal component average values. Furthermore, the results of the SOM indicated that, similar to type A, principal components 1 and 3 had lower values and relatively concentrated distributions, while the values of principal component 2 were quite high, but relatively dispersed distributions. In light of these individual aspects, this type is characterized by a deteriorating role, although in the past it was a nucleus of vitalization. In addition, the location environment is stark, and the degree of effort in terms of regional management direction is low, particularly with regard to urbanization and localization. This results in a low degree of community vitality and requires regenerative strategies based on new perspectives.

Type C: Of the 100 small rural cities that were the subjects of our study, 27 cities ( $27 \%$ of our subjects) belong to Type C. When these cities were surveyed based on the individual indicators shown in Table 2., the following characteristics emerged: (1) Many cities had sought to upgrade and reinforce their highspeed transportation infrastructure, including airports, Shinkansen bullet trains, and expressways. (2) Many exhibited an urban arrangement structure in lemniscate form, with a high degree of centrality as a city. (3) Many cities manifested weak urbanity, as they were established through mergers of agricultural and fishing towns and villages.

The results of typification were derived with such characteristics in mind. First, the average values of the principal components, as shown in Table 5., were -13.56 for principal component 1 (urban location infrastructure), -16.33 for principal component 2 (urban
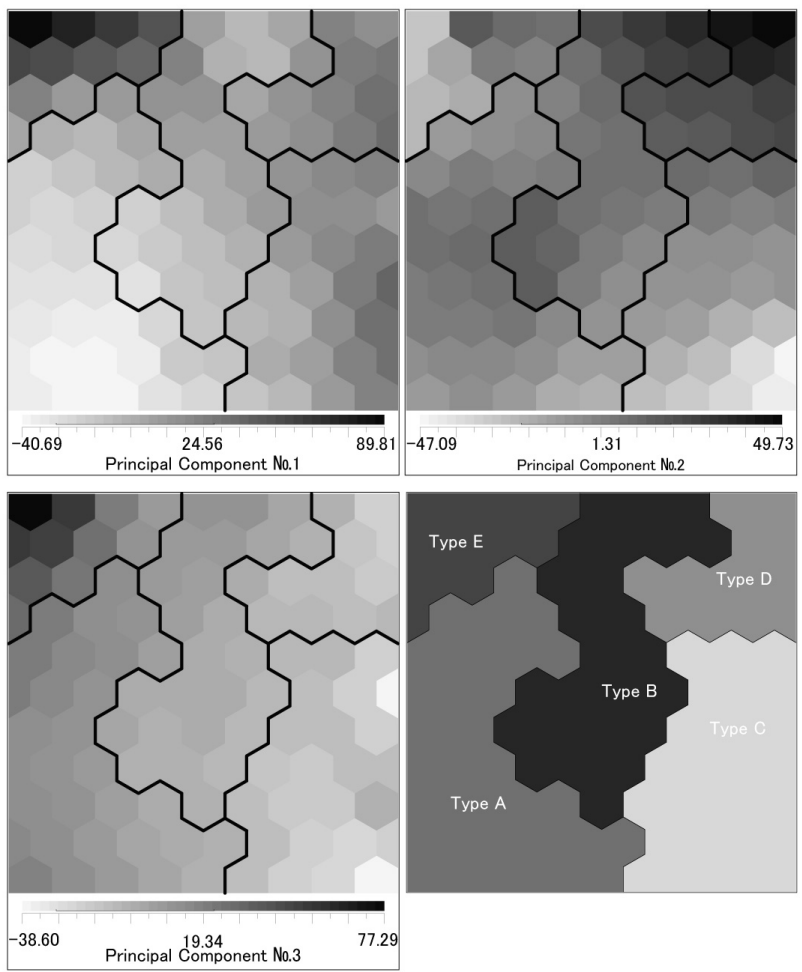

Fig.1. Result of SOM

Table 5. Typological Characteristics

\begin{tabular}{|c|r|r|r|r|r|r|r|r|r|}
\hline \multirow{2}{*}{ Type } & Frequency & \multicolumn{3}{|c|}{ Principal Component } & \multirow{2}{*}{ Type } & Frequency & \multicolumn{3}{|c|}{ Principal Component } \\
\cline { 3 - 9 } & & No.1 & No.2 & No.3 & & No.1 & No.2 & No.3 \\
\hline A & 33 & -28.42 & -2.25 & 9.70 & D & 12 & 23.28 & 32.03 & -12.19 \\
\hline B & 19 & -6.46 & 11.32 & -0.77 & E & 9 & 46.12 & -9.36 & 34.36 \\
\hline C & 27 & 13.56 & -16.33 & -17.35 & & & & \\
\hline
\end{tabular}

Table 6. Cities in Each Type

\begin{tabular}{|c|c|c|c|c|c|c|c|}
\hline \multicolumn{8}{|c|}{ Type A } \\
\hline 1 & Kuroishi & 28 & Soma & 53 & Ina & 76 & Iyomishima \\
\hline 3 & Towada & 33 & Murakami & 54 & Komagane & 78 & Suzaki \\
\hline 4 & Ofunato & 35 & Itoigawa & 56 & Omachi & 79 & Nakamura \\
\hline 8 & Kuji & 42 & Wajima & 59 & Kurayoshi & 94 & Hondo \\
\hline 11 & Kesennuma & 45 & Komatsu & 61 & Masuda & 97 & Saito \\
\hline 12 & Shiroishi & 46 & Ono & 62 & Ota & 98 & Izumi \\
\hline 15 & Honjo & 48 & Fujiyoshida & 69 & Miyoshi & & \\
\hline 17 & Yuzawa & 49 & Tsuru & 74 & Ozu & & \\
\hline 25 & Haramachi & 51 & Otsuki & 75 & Kawanoe & & \\
\hline \multicolumn{8}{|c|}{ Type B } \\
\hline 2 & Goshogawara & 43 & Kaga & 63 & Yasugi & 92 & Kashima \\
\hline 16 & Oga & 47 & Sabae & 64 & Hirata & 95 & Yamaga \\
\hline 27 & Kitakata & 50 & Yamanashi & 73 & Kanonji & 96 & Uto \\
\hline 38 & Uozu & 52 & Komoro & 77 & Tosa & 99 & Ibusuki \\
\hline 39 & Himi & 55 & Nakano & 90 & Imari & & \\
\hline \multicolumn{8}{|c|}{ Type C } \\
\hline 5 & Mizusawa & 21 & Murayama & 31 & Tokamachi & 70 & Otake \\
\hline 6 & Hanamaki & 22 & Nagai & 32 & Mitsuke & 71 & Yanai \\
\hline 7 & Kitakami & 23 & Tendo & 36 & Gosen & 81 & Amagi \\
\hline 9 & Esashi & 24 & Higashine & 65 & Ihara & 85 & Buzen \\
\hline 14 & Kakuda. & 26 & Sukagawa & 66 & Soja & 89 & Tosu \\
\hline 19 & Sagae & 29 & Nihonmatsu & 67 & Innoshima & 91 & Takeo \\
\hline 20 & Kaminoyama & 30 & Ojiya & 68 & Futyu & & \\
\hline \multicolumn{8}{|c|}{ Type D } \\
\hline 10 & Furukawa & 37 & Shirane & 60 & Sakaiminato & 82 & Chikugo \\
\hline 18 & Omagari & 40 & Namerikawa & 72 & Zentsuji & 83 & Okawa \\
\hline 34 & Tsubame & 41 & Tonami & 80 & Yanagawa & 93 & Tamana \\
\hline \multicolumn{8}{|c|}{ Type E } \\
\hline 13 & Natori & 58 & Shiojiri & 87 & Chikushino & & \\
\hline 44 & Matto & 84 & Yukuhashi & 88 & Munakata & & \\
\hline 57 & Chino & 86 & Ogori & 100 & Kokubu & & \\
\hline
\end{tabular}


spatial formation), and -17.35 for principal component 3 (industrial vitality). A comparison of these results with the average values of the principal components for types $A, B$, and $D$ revealed that, in terms of principal components 2 and 3, this type had the lowest level of the four. These two components were therefore considered fragile, which was a significant issue. Furthermore, the results of the SOM indicated high values for principal component 1, with a dispersed distribution characteristic. On the other hand, principal components 2 and 3 were low, with a relatively concentrated distribution. In light of these individual aspects, this type is characterized as being based on the gaps existing between them, which are a function of whether these cities utilized favorable environments and conditions to their advantage for urban spatial formation. However, their urban environment is such that they could easily have been subjected to stimuli for extrinsic development, particularly centered on transportation conditions.

Type D: Of the 100 small rural cities that were the subjects of our study, 12 cities (12\% of our subjects) belong to Type D. When these cities were surveyed based on the individual indicators shown in Table 2., the following characteristics emerged: (1) Many had favorable urban location environmental conditions. (2) They were strongly influenced by major rural cities in particular, such as a prefectural capital city. (3) Strategies for regional management direction were more often implemented than in other types, with the exception of industrialization efforts. The effects were also explicit.

The results of typification were derived with such characteristics in mind. First, the average values of the principal components, as shown in Table 5, were 23.28 for principal component 1 (urban location infrastructure), 32.03 for principal component 2 (urban spatial formation), and -12.19 for principal component 3 (industrial vitality). A comparison of these results with the average values of the principal components for types $\mathrm{A}, \mathrm{B}$, and $\mathrm{C}$ revealed that this type had the highest level for principal components 1 and 2. On the other hand, principal component 3 had a value of -12.19 , which diverged from the favorable values of the other types. The results of the SOM indicated a high value for principal component 1 , with a relatively concentrated distribution characteristic. On the other hand, a high value was indicated for principal component 2 , but with a dispersed distribution characteristic. Low values with a concentrated distribution characteristic emerged for principal component 3 . Thus, distinct characteristics emerged for each principal component. In light of these individual aspects, this type had the most advantageous urban environment of the four, and it appears that the implementation of urban spatial formation would be easy. However, the core of such actions was primarily extrinsic, and the degree of effectiveness was considered to be governed by how intrinsic and voluntary implementations were combined, as well as whether and how well they were coordinated.

The conclusions regarding the following trends are based on the characteristics of each type: (1) Small rural cities can be categorized into four types and three principal components, which are derived from principal component loads. (2) Most cities (33 cities) are classified as Type A cities. (3) Type D had a favorable environment in terms of average values for components by type. However, the trend was that principal components 1 and 3 represented Type A and principal component 3 represented Type C. (4) The results of the SOM indicated that the urban spatial formation for principal component 2 determined the characteristics of small rural cities.

\section{Conclusion and Future Issues}

Based on this study, authors conclude the following with regard to the regional characteristics of small rural cities:

(1) It is believed that three principal components are effective for understanding the characteristics of small rural cities: 1) "Urban location infrastructure," which values factors such as transportation conditions and the existence and influence of surrounding cities among the original regional conditions of small rural cities; 2) "Urban spatial formation" refers to municipal efforts to solve the issues of small rural cities and to support and enhance growth as urban cities; and 3) "Industrial vitality" is a major component supporting small rural cities as a result of a joint effort of location infrastructure and urban spatial formation as regional management directions.

(2) Through a typological analysis, authors obtained four kinds of characteristics for each type.

- Type A: Compared to the other types, these cities' external environmental conditions such as transportation conditions, and existence and influence of surrounding cities are considered unfavorable. Their core policy is industrialization; however, this does not provide enough motivation to revitalize the regional economy. A total of 33 cities, accounting for $33 \%$ of all subjects, belong to this type, making it the largest category.

- Type B: Although these cities were once vital, their functions have weakened over time and their current locational environment as cities is unfavorable. They need revitalization based on a new perspective.

- Type C: These cities are in an urban environment where stimuli for extrinsic development can be easily introduced. This type has a high degree of centrality and transportation conditions, and urban arrangement structures are in lemniscate form. Utilization of these favorable environments/conditions for urban spatial formation determines the difference between the ranks of each city.

- Type D: These cities boast the most favorable urban 
location environment. However, regional management direction focuses on industrialization where extrinsic developmental opportunities can be easily introduced, and the coordination and combination of voluntary and intrinsic implementation efforts is not enough.

(3) Authors believe these results offer suggestions for formulating systematic development policies for small rural cities.

The following are possible areas of future research:

(1) A comparison between the regional characteristic analysis of the conceptual small rural city indicated in reference (11) and the analysis results of this study.

(2) A consideration of the comparative evaluation by types, based on (1) above.

(3) An analysis of the urbanization process using specific small rural cities as models, based on the typological results, as well as the establishment of a plan theory for intrinsic development centering on "man and matter," based on the understanding of such results.

\section{Notes}

Regional Area

In this study, data from The Ministry of Land, Infrastructure, and Transport (formerly known as National Land Agency) were used for regional segmentation. At the time, Hokkaido and Okinawa had a different policy for the regional formation process, and were thus excluded from the 28 prefectures used as subjects for this study.

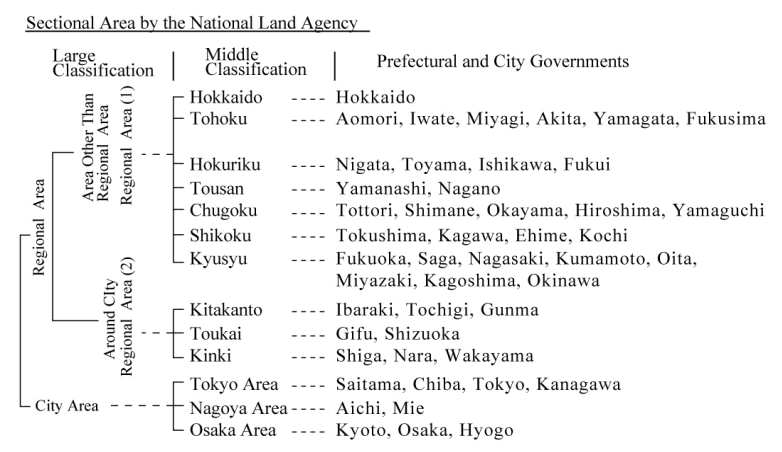

2 Small Rural Cities

Yukinobu Wada (1989) and (1990) sought to promote the Municipal Mergers Law enacted in 1953 for small rural cities and the idea that "conditions for city establishment shall not greatly exceed a population of 50,000 in the merger of established towns and villages situated in regional areas." For the purpose of this study, authors adopted the following definition of a "small rural city": "Enactment of the Law for the Promotion of Municipal Mergers of 1953 first became an issue in the period between 1950 and 1958. It focused on municipalities that at the time of the merger became cities with a population between 30,000 and $100,000 . "$

\section{Self-sustainable settlement}

A self-sustainable settlement plan is a government policy intended to provide settlements for rural areas expecting a rapidly decreasing and aging population. More specifically, it is a government policy with which municipalities, which are basic units of autonomous communities, mutually cooperate in sharing roles to secure essential living functions for each region to protect the lives and lifestyles of residents in the local community. The policy is also intended for economic growth, led by domestic demand in local regions, through industrial promotions, as well as relocations and interchanges made possible by the cooperation of municipalities. The Ministry of Internal Affairs and Communications is promoting the policy.

$4 \quad$ Municipality mergers

The progress of the national territory with equilibrium, responsive actions for administrative demands in widespread areas, and the promotion of a decentralized government are cited as significant reasons for the merging of municipalities. Through mergers, municipalities in Japan have been decreasing in number and increasing in size. As of January 1, 2013, there were 1,719 municipalities, less than a 40th of the figure in the early Meiji Era (from 1868). Historically, intense mergers of municipalities occurred during three periods, known as the Great Mergers of Meiji, Showa, and Heisei. During the Great Merger of Showa, the number of towns and villages dropped from approximately 10,000 to about 3,500 within a few years. At the same time, the number of cities increased by over 200. Many of these cities are now classified as "small rural cities." Furthermore, the number of municipalities dropped from about 3,500 to 1,719 during the Great Merger of Heisei. This increased the size of the "small rural cities" created by the Great Merger of Showa, and created new "small rural cities."

Self-organizing map (SOM-Ward)

SOM-Ward is a clustering method to create topological order in data with regard to objects intricately distributed in multidimensional space. In this study, authors considered the hierarchical method (nearest neighbor method, furthest neighbor method, group average method, Ward method), which is a popular clustering method, and the partitioning-optimization method (K-means method). However, since these methods comprise data showing non-linear relations, authors decided to employ the SOMWard method. The results of clustering using a self-organizing map need to be represented on a map. In this study, authors used a map to represent the results of clustering using gray-scale density to express high and low scores for the principal component. Authors could identify trends in the high and low values of the scale, and distribution as typological characteristics from the map. Also, while not mentioned in this study, authors could create a similar map to analyze trends for individual indicators.

Urban industry

In Japan, there are four articles regarding the conditions of forming a city according to the Local Autonomy Act, irrespective of the Act on Special Provisions of the Merger of Municipalities. One article stipulates that the ratio of employment in secondary and tertiary industries must account for more than $60 \%$ of employment overall. This is a condition under the "industrial urban business category." However, many small rural cities do not fulfill all four requirements.

\section{References}

Part of the present study was reported in the following research: References 11, 12, 17, and 18 .

1) Cheong-Ho Park, Ja-Hoon Koo (2014) "An Analysis of the Influential Relationship between Cultural Promotion Activities and Social Capital in the Traditional Market: A Comparative View with Routine Merchant Activities," Journal of Asian Architecture and Building Engineering, Vol. 13, No. 1, pp.71-78.

2) Hatem Mahmoud, Takafumi Arima (2011) "A Web-Based Public Participation System that Supports Decision Making," Journal of Asian Architecture and Building Engineering, Vol. 10, No. 1, pp.77-84.

3) Heather Podoll (2000) "A Case Study of The Davis Farmers' Market: Connecting Farms and Community," UC Sustainable Agriculture Research and Education Program.

4) James Weston Livingood, Norman O. Burns, Patrice H. Glass, (2001) "Chattanooga: an Illustrated History," American Historical Press. 
5) Kiyofumi Shirai, Yukinobu Wada (1995) "On the classification of small cities in the provincial area by analyzing the inflow and outflow of commuters: Study on the Populational Structure of Small Cities in the Provincial Area Part 7." Summaries of Technical Papers of Annual Meeting, Architectural Institute of Japan, F-1, Vol. 1995, pp.323-324.

6) Kohonen, T. (2005) Self-Organizing Maps, Revised Edition. Springer, Japan.

7) Keiro Hattori (2007) "Urban development of small- and mediumsized cities that have overcome decline in America," Gakugei Publishing Company, Japan.

8) Perter Pollock (1998) "Controlling Sprawl in Boulder: Benefits and Pitfalls," Proceedings of the 1998 National Planning Conference.

9) Robert Rosen (1997) "A Short History of Charleston." University of South Carolina.

10) Robert R. Weyeneth (2000) "Historic Preservation for a Living City," University Of South Carolina.

11) Masao Ishii, Hitoshi Sasao (2000) "Study of Regional Character of Small Towns in Countryside and Forming the Social Basement of Intelligence." Planning Administration, Vol. 23, No. 4, pp.28-38.

12) Masao Ishii, Hirotomo Ouchi, Satoshi Yamada (2007) "Study on regional characteristics and types of small rural towns." Nihon University, Faculty of Engineering Science 40th Production. Academic Lecture, Architecture Group Abstracts 4-51, pp.187190.

13) Min Jung Lee, Dong-Eon Lee (2014) "Questioning Beliefs Surrounding Urban Sustainability: The Need for a Contextual Urban Model," Journal of Asian Architecture and Building Engineering, Vol. 13, No. 1, pp.163-170.

14) Tokumi Odagiri (2007) "Issues of the National Land Sustainability Plan for Rural Areas." Journal of Rural Planning Association, Vol. 26, No. 2, pp.99-104.

15) Technical Committee on the Initiative for Independent Settlements (2008) "Technical Committee on the Initiative for Independent Settlements Study Group Report." Ministry of Internal Affairs and Communications.

16) Teruhiko Asano (2000) "Introduction to Actual Multivariate Analysis. Second edition. Kodansha.

17) Takashi Kuroiwa, Yuji Sugita, Yuta Takahashi, Hirotomo Ouchi, Mitsuto Matsubara (2009a) "Classification of cities using selforganizing maps." Proceedings of the General Conference of Electronic Information Transfer. A, A-6-5, p.169.

18) Takashi Kuroiwa, Yuji Sugita, Hirotomo Ouchi, Mitsuto Matsubara (2009b) "Analysis of city characteristics using selforganizing maps." Proceedings of the Electronic Information Transfer Academic Society. A, A-6-1, p.125.

19) Yukinobu Wada (1989) "Study on structure of population in small cities in a provincial area by analyzing population and DID population." Journal of Architecture, Planning and Environmental Engineering (Transactions of AIJ)," No. 406, pp.111-121.

20) Yukinobu Wada (1990) "Study on structure of population in small cities in a provincial area by analyzing industrial population." Journal of Architecture, Planning and Environmental Engineering (Transactions of AIJ)," No. 418, pp.83-93. 